\title{
What caused the significant increase in Atlantic Ocean heat content since the mid-20th century?
}

\author{
Sang-Ki Lee, ${ }^{1,2}$ Wonsun Park, ${ }^{3}$ Erik van Sebille, ${ }^{4}$ Molly O. Baringer, ${ }^{2}$ Chunzai Wang, ${ }^{2}$ \\ David B. Enfield, ${ }^{1,2}$ Stephen G. Yeager, ${ }^{5}$ and Ben P. Kirtman ${ }^{4}$ \\ Received 10 July 2011; revised 8 August 2011; accepted 8 August 2011; published 8 September 2011.
}

[1] As the upper layer of the world ocean warms gradually during the 20th century, the inter-ocean heat transport from the Indian to Atlantic basin should be enhanced, and the Atlantic Ocean should therefore gain extra heat due to the increased upper ocean temperature of the inflow via the Agulhas leakage. Consistent with this hypothesis, instrumental records indicate that the Atlantic Ocean has warmed substantially more than any other ocean basin since the mid20th century. A surface-forced global ocean-ice coupled model is used to test this hypothesis and to find that the observed warming trend of the Atlantic Ocean since the 1950s is largely due to an increase in the inter-ocean heat transport from the Indian Ocean. Further analysis reveals that the increased inter-ocean heat transport is not only caused by the increased upper ocean temperature of the inflow but also, and more strongly, by the increased Agulhas Current leakage, which is augmented by the strengthening of the wind stress curl over the South Atlantic and Indian subtropical gyre. Citation: Lee, S.-K., W. Park, E. van Sebille, M. O. Baringer, C. Wang, D. B. Enfield, S. G. Yeager, and B. P. Kirtman (2011), What caused the significant increase in Atlantic Ocean heat content since the mid-20th century?, Geophys. Res. Lett., 38, L17607, doi:10.1029/2011GL048856.

\section{Introduction}

[2] Recently updated and bias-corrected instrumental records indicate that the heat content of the Atlantic Ocean in the upper $700 \mathrm{~m}$ has substantially increased during the $1970 \mathrm{~s}-2000 \mathrm{~s}$ at a rate $\left(\sim 2.0 \times 10^{22} \mathrm{~J}\right.$ per decade $)$ almost matching that of the Pacific Ocean $\left(\sim 1.5 \times 10^{22} \mathrm{~J}\right.$ per decade $)$ and Indian Ocean $\left(\sim 0.5 \times 10^{22} \mathrm{~J}\right.$ per decade) combined [Levitus et al., 2009], even though the Atlantic Ocean covers less than $20 \%$ of the global ocean in surface area. Climate model experiments with and without anthropogenic greenhouse forcing have shown that the observed warming of the global ocean since the mid-20th century could be largely attributed to the anthropogenic greenhouse effect [Levitus et al., 2001; Barnett et al., 2001, 2005]. However, a question

\footnotetext{
${ }^{1}$ Cooperative Institute for Marine and Atmospheric Studies, University of Miami, Miami, Florida, USA.

${ }^{2}$ Atlantic Oceanographic and Meteorological Laboratory, NOAA, Miami, Florida, USA.

${ }^{3}$ Leibniz Institute of Marine Sciences at University of Kiel (IFMGEOMAR), Kiel, Germany.

${ }^{4}$ Rosenstiel School for Marine and Atmospheric Science, University of Miami, Miami, Florida, USA. USA.

${ }^{5}$ National Center for Atmospheric Research, Boulder, Colorado,

Copyright 2011 by the American Geophysical Union. 0094-8276/11/2011GL048856
}

still remains as to why the warming trend in the Atlantic Ocean is substantially larger than that in other ocean basins. This is also an important question for our understanding of past, present and future climate variability on regional and global scales because, for instance, tropical precipitation and Atlantic hurricane activity in the 21 st century could be affected by a differential inter-ocean warming [e.g., Lee et al., 2011].

[3] Deep convective mixing over the North Atlantic sinking regions could cause the subpolar North Atlantic sea surface temperatures (SSTs) to become relatively insensitive to the anthropogenic greenhouse effect, and thus decreasing the longwave heat loss at the sea surface and increasing the radiative heating associated with anthropogenic greenhouse gases. However, this hypothesis appears to be inconsistent with the observed cooling trend of the subpolar North Atlantic Ocean in the upper $1500 \mathrm{~m}$ during the 1950s-1990s [e.g., Lozier et al., 2010].

[4] Perhaps, the answer to this conundrum can be found in the global overturning circulation, the large scale ocean circulation that connects the Pacific, Indian and Southern Oceans to deep convection in the North Atlantic sinking regions, carrying with it heat, freshwater and carbon, etc [Broecker, 1987]. As the upper layer of the world ocean warms gradually, the inter-ocean heat transport via the global overturning circulation should increase given that the radiative heating associated with the anthropogenic greenhouse effect is more or less uniform over the world ocean [Palmer et al., 2007]. The increased inter-ocean heat transport should further warm the Atlantic Ocean since the Atlantic basin is characterized by advective heat convergence (i.e., the northward ocean heat transport at $30^{\circ} \mathrm{S}$ in the South Atlantic is always positive) due to the Atlantic Meridional Overturning Circulation (AMOC), which is the Atlantic component of the global overturning circulation. The Atlantic warming should continue until the deep layer of the Atlantic Ocean fully adjusts to the increased radiative heating over the world ocean and exports the warm water out of the basin at depth or until the AMOC weakens due to the increased buoyancy in the North Atlantic sinking regions. This hypothesis is in line with the results from Palmer and Haines [2009] who used historical hydrographic observations from 1970 to 2000 to make quantitative estimates of the contribution to ocean heat content changes from the ocean heat transport convergence (estimated by deepening of the reference isotherm of $14^{\circ} \mathrm{C}$ ) versus surface heating (estimated by warming above the $14^{\circ} \mathrm{C}$ isotherm). They found that the ocean heat transport convergence dominates only in the Atlantic basin. Grist et al. [2010] used a high-resolution global ocean model forced with historical surface meteorological fields to find a consistent result. 
[5] Changes in the strength and spatial structure of the AMOC could also modulate the ocean heat transport convergence in the Atlantic basin, and thus may have contributed to the observed warming of the Atlantic Ocean since the mid-20th century. However, it is difficult to attribute the increased Atlantic Ocean heat content to AMOC variability because there is no reliable long-term instrumental record of the AMOC. It appears that an ocean model-based reconstruction is likely to be our best chance for assessing the history of AMOC in the 20th century because the relatively long time series of estimated surface flux fields, which constrain ocean-ice coupled models, are available from atmospheric reanalysis products. Therefore, in the following sections, we use a series of global ocean-ice model simulations to explore why the Atlantic Ocean has warmed much more than any other ocean basin since the mid-20th century.

\section{The 20th Century Reanalysis (20CR)}

[6] The paucity of observational hydrographic data makes it a challenge for proper initialization a global ocean model in the mid-20th century. An alternative approach is to start an ocean model simulation sufficiently earlier than the mid20th century. This will finesse issues involving the model initialization. However, none of the surface-forced ocean model studies so far has been simulated with the surface forcing prior to the mid-20th century because the surface forcing data, which are typically derived from atmospheric reanalysis products, are limited to the last 50-60 years. Recently, the newly developed NOAA-CIRES 20th Century Reanalysis (20CR) has been completed [Compo et al., 2011]. The 20CR provides the first estimate of global surface fluxes spanning the late 19th century and the entire 20th century (1871-2008) at daily temporal and $2^{\circ}$ spatial resolutions.

\section{Model Experiments}

[7] The global ocean-ice coupled model of the NCAR Community Climate System Model version 3 (CCSM3) forced with the 20CR is used as the primary tool in this study. The ocean model is divided into 40 vertical levels. Both the ocean and ice models have 320 longitudes and 384 latitudes on a displaced pole grid with a longitudinal resolution of about 1.0 degrees and a variable latitudinal resolution of approximately 0.3 degrees near the equator. See Doney et al. [2007] for more detailed descriptions about the CCSM3 ocean-ice model (CCSM3_POP hereafter).

[8] To spin up the model, a fully coupled (atmosphereland-ocean-ice) CCSM3 control experiment is performed for 700 years with the pre-industrial climate condition of the 1870s. The 700th year output of the CCSM3 spin-up run is then used to initialize the CCSM3_POP, which is further integrated for 200 more years using the daily 20CR surface flux fields for the period of 1871-1900. In the CCSM3_POP spin-up run and a series of CCSM3_POP experiments described below, the wind stress vector, shortwave radiative heat flux, downward longwave radiative heat flux and precipitation rate are specified, whereas the upward longwave radiative heat flux and turbulent surface fluxes are imposed interactively by using the wind speed, air temperature and specific humidity along with the model-produced SST. To incorporate the impact of atmospheric noise, which plays a crucial role in the thermohaline convection and deep-water formation in the North Atlantic sinking regions (P. Chang, personal communication, 2011), during the spin-up the surface forcing fields in each model year are randomly selected from the period 1871-1900. In the 200 years of the CCSM3_POP spin-up run, the simulated world ocean heat content in the upper $700 \mathrm{~m}$ shows no sign of drift after about 150 years. Nevertheless, the 900 years of spin-up may not be long enough for deep oceans to reach a quasi-equilibrium state, if there is any. Therefore, to check and ensure that there is no long-term model drift in the real-time experiments to be described below, the CCSM3 POP spin-up run is continued for additional 138 years, which is referred to as the reference experiment (EXP_REF).

[9] After the total of 900 years of spin-up runs, three model experiments are performed as summarized in Table S1 in the auxiliary material. ${ }^{1}$ In the control experiment (EXP_CTR), the CCSM3_POP is integrated for 1871-2008 using the real-time daily $20 \mathrm{CR}$ surface flux fields. The next two experiments are idealized experiments designed to understand the Atlantic Ocean heat content change with and without the influence of the northward heat transport change at $30^{\circ} \mathrm{S}$. The remote ocean warming experiment (EXP_REM) is identical to EXP_CTR except that the surface forcing fields north of $30^{\circ} \mathrm{S}$ are from the daily 20CR surface flux fields for the period of 1871-1900 exactly like EXP_REF, whereas those south of $30^{\circ} \mathrm{S}$ are as in EXP_CTR. Similar to EXP REM, the Atlantic Ocean warming experiment (EXP ATL) is also identical to EXP_CTR except that the surface forcing fields south of $30^{\circ} \mathrm{S}$ are from EXP_REF, whereas those north of $30^{\circ} \mathrm{S}$ are from EXP_CTR. Note that the Atlantic Ocean warms only through anomalous surface heating in EXP_ATL, and only through anomalous northward ocean heat transport at $30^{\circ} \mathrm{S}$ in EXP_REM, respectively.

\section{Results}

[10] Figure 1a shows the time series of simulated Atlantic Ocean heat content in the upper $700 \mathrm{~m}$ in reference to the 1871-1900 baseline period obtained from the three model experiments, along with the observed heat content of the Atlantic Ocean. For a better visual comparison with the simulations, the observed heat content, which is recomputed from Levitus et al. [2009] for the Atlantic basin from $30^{\circ} \mathrm{S}$ to $75^{\circ} \mathrm{N}$, is referenced in such a way that it matches the simulated heat content in EXP_CTR averaged during 19551964. The simulated heat content of the Atlantic Ocean in EXP_CTR increases moderately during the first half of the 20th century, after which it increases substantially. During the $1970 \mathrm{~s}-2000 \mathrm{~s}$, it increases by $5 \sim 6 \times 10^{22} \mathrm{~J}$. This large increase is reasonably close to the observed Atlantic Ocean heat content increase during the same period [Levitus et al., 2009]. In EXP ATL, the North Atlantic Ocean heat content increases by only $\sim 2 \times 10^{22} \mathrm{~J}$ during the $1970 \mathrm{~s}-2000 \mathrm{~s}$; thus the local variable surface fluxes alone cannot explain the observed North Atlantic Ocean heat content increase. In EXP REM, on the other hand, the Atlantic Ocean heat content increases by $3 \sim 4 \times 10^{22} \mathrm{~J}$ during the $1970 \mathrm{~s}-2000$ s explaining a large portion of the simulated trend in EXP_CTR. The simulated Atlantic Ocean heat content in EXP_REF does not show any long-term model drift affirming that the

\footnotetext{
${ }^{1}$ Auxiliary materials are available in the HTML. doi:10.1029/ 2011GL048856.
} 
CCSM3_POP: ATL OCN Heat Content \& Budget

(a) Atlantic Ocean Heat Content

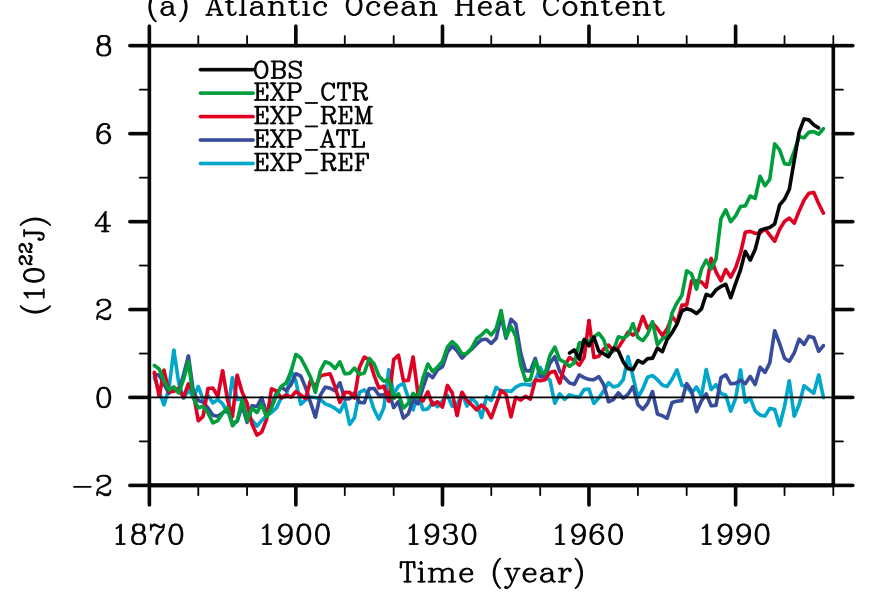

(b) Atlantic Ocean Heat Budget (EXP_CTR)

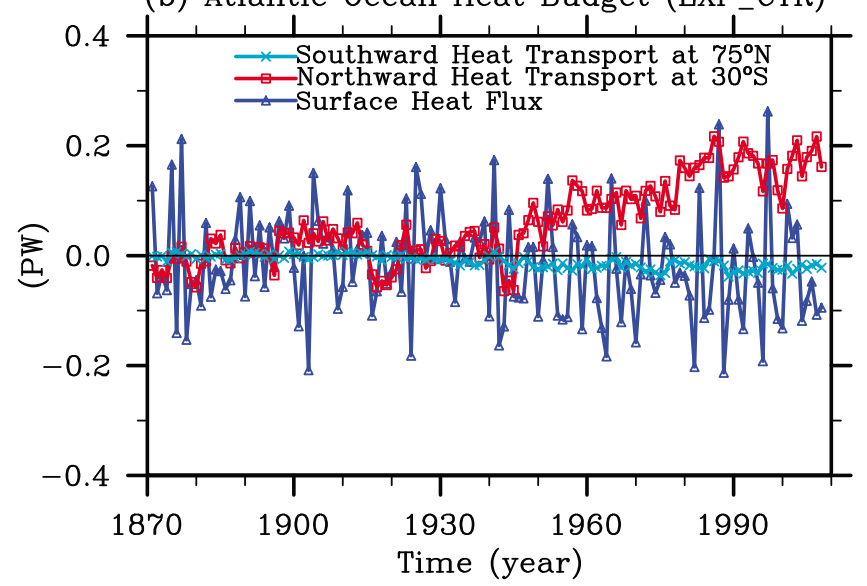

Figure 1. (a) Simulated Atlantic Ocean heat content change in the upper $700 \mathrm{~m}$ in reference to the 1871-1900 baseline period obtained from the four model experiments. The thick black line in Figure 1a is the observed heat content of the Atlantic Ocean, which is recomputed from Levitus et al. [2009] for the Atlantic basin from $30^{\circ} \mathrm{S}$ to $75^{\circ} \mathrm{N}$. (b) Simulated heat budget terms for the Atlantic Ocean obtained from EXP_CTR, all referenced to the 1871-1900 baseline period.

increased Atlantic Ocean heat content in EXP_CTR is not an artifact of the model simulation.

[11] Figure $1 \mathrm{~b}$ shows the heat budget terms for the Atlantic Ocean, obtained from EXP_CTR, namely the southward heat transport for the entire water column at $75^{\circ} \mathrm{N}$, the northward heat transport for the entire water column at $30^{\circ} \mathrm{S}$, and the surface heat flux into the Atlantic Ocean between $30^{\circ} \mathrm{S}$ and $75^{\circ} \mathrm{N}$, all referenced to the $1871-1900$ baseline period. The simulated northward heat transport at $30^{\circ} \mathrm{S}$ is about $0.1 \sim 0.2 \mathrm{PW}$ larger in the 1960s-2000s period than in the earlier periods, consistent with the large Atlantic Ocean heat content increase in EXP_CTR (Figure 1a). On the other hand, it is clear that both the surface heat flux and the northward Atlantic Ocean heat transport at $75^{\circ} \mathrm{N}$ have little impact on the Atlantic Ocean warming since the mid-20th century. Therefore, these model results fully support the hypothesis that the enhanced warming of the Atlantic Ocean since the mid-20th century is largely due to the increased ocean heat transport into the Atlantic basin across $30^{\circ} \mathrm{S}$.

\section{AMOC Variability at $30^{\circ} \mathrm{S}$}

[12] Dong et al. [2009] showed that the northward heat transport in the South Atlantic near $30^{\circ} \mathrm{S}$ could be directly scaled with the AMOC strength. Therefore, the baroclinic volume transport (i.e., AMOC) in the South Atlantic at $30^{\circ} \mathrm{S}$ and its contribution to the large increase in the simulated ocean heat transport into the Atlantic basin are explored in this section.

[13] Figure 2a shows the time-averaged AMOC during 1979-2008 obtained from EXP_CTR. The simulated maximum strength of the AMOC at $35^{\circ} \mathrm{N}$ is only $11 \mathrm{~Sv}(1 \mathrm{~Sv}=$ $10^{6} \mathrm{~m}^{3} \mathrm{~s}^{-1}$ ), which is smaller than the observed range of $14 \sim 20 \mathrm{~Sv}$. Increasing the vertical diffusivity in the model boosts the AMOC strength [e.g., Mignot et al., 2006]. However, since other model features deteriorate with the increased vertical diffusivity, the vertical diffusivity is not increased in this study. Despite the smaller maximum strength, the overall spatial structure of the simulated AMOC is quite CCSM3_POP (EXP_CTR): AMOC

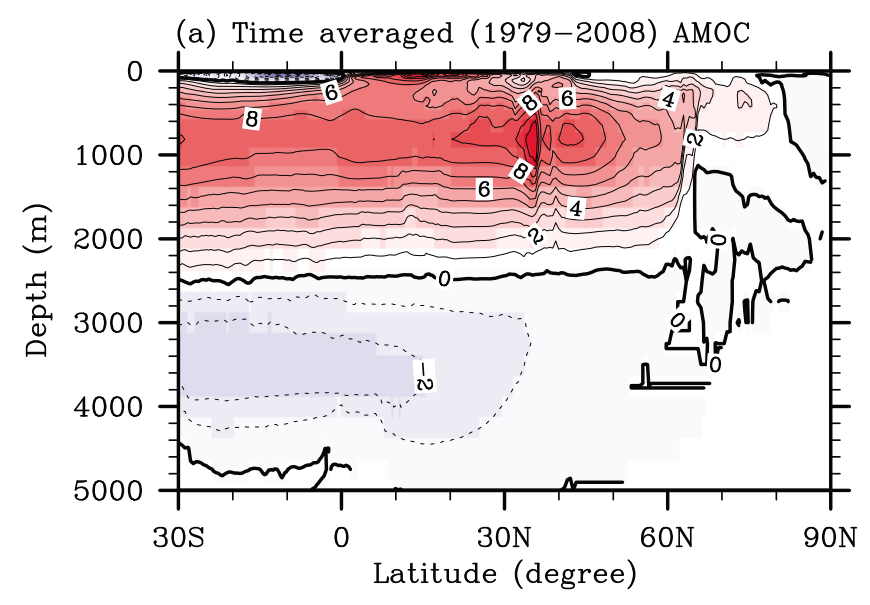

(b) AMOC index (Max at $30^{\circ} \mathrm{S}$ )

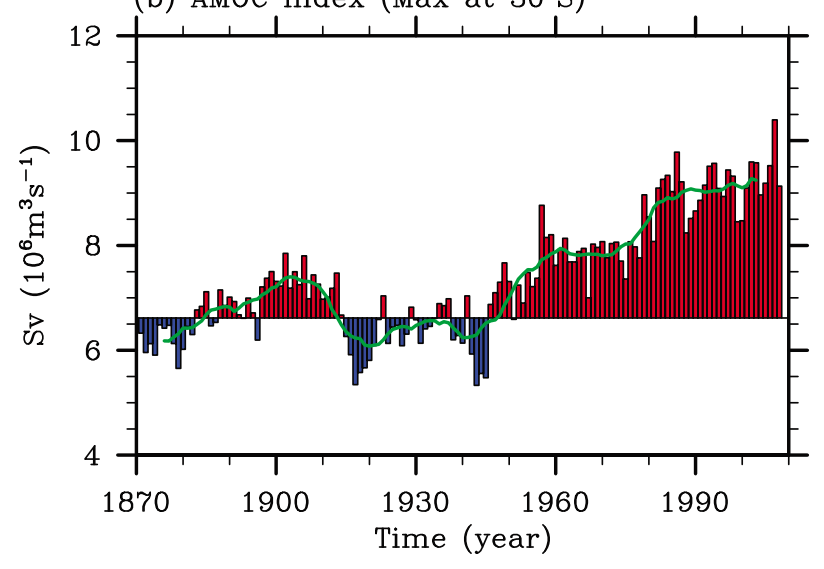

Figure 2. (a) Time-averaged AMOC during 1979-2008 and (b) time series of the simulated AMOC index (maximum overturning streamfunction) at $30^{\circ} \mathrm{S}$ obtained from EXP CTR. The green line in Figure $2 b$ is obtained by performing a 11-year running average to the AMOC index. 

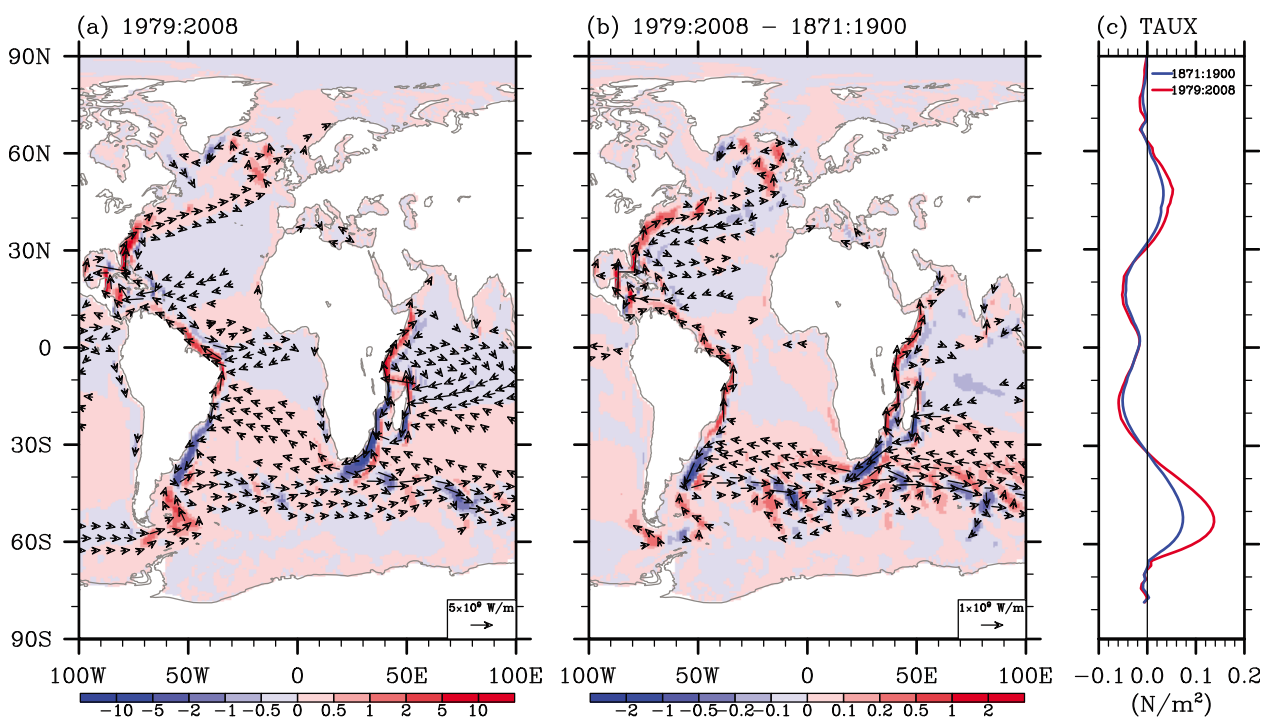

Figure 3. (a) Simulated pathways of the northward heat transport (contours) and heat transport vector (vectors) in the upper $3000 \mathrm{~m}$ for 1979-2008 obtained from EXP_CTR. The unit is $1 \times 10^{9} \mathrm{~W} / \mathrm{m}$. (b) Differences in the simulated northward heat transport (contours) and heat transport vector (vectors) between 1979-2008 and 1871-1900 periods, obtained from EXP_CTR. Red color indicates northward heat transport, while blue color indicates southward heat transport. (c) Globally averaged zonal wind stress for 1871-1900 and for 1979-2008 periods, obtained from the 20CR.

close to that derived from observations [e.g., Lumpkin and Speer, 2007].

[14] Figure 2b shows the time series of the simulated AMOC index (maximum overturning streamfunction) at $30^{\circ} \mathrm{S}$. It clearly shows that the AMOC at $30^{\circ} \mathrm{S}$ increases after the 1940s, suggesting that the increased northward heat transport in the South Atlantic at $30^{\circ} \mathrm{S}$ (Figure 1b) is linked to the increased baroclinic volume transport at $30^{\circ} \mathrm{S}$. The AMOC at $30^{\circ} \mathrm{S}$ in EXP_REM has a similar increase as in EXP_CTR (Figure S1a). On the other hand, the AMOC at $30^{\circ} \mathrm{S}$ in EXP_ATL (Figure S1b) does not show a large long-term trend. These results strongly suggest that the processes within the Atlantic Ocean do not cause the increased AMOC strength at $30^{\circ} \mathrm{S}$ after the 1940s in EXP_CTR. In other words, the AMOC increase at $30^{\circ} \mathrm{S}$ is pushed from the outside, rather than pulled from the inside.

[15] The effect of the increased AMOC versus the increased upper ocean temperature in the South Atlantic at $30^{\circ} \mathrm{S}$ can be assessed by using the model output fields from EXP CTR. Using only the Eulerian-mean component of the meridional flow and the ocean temperature, we find that the purely thermal effect (i.e., only due to ocean temperature changes) accounts for about $20 \%$ increase of the heat transport at $30^{\circ} \mathrm{S}$ between $1871-1900$ and 1979-2008 periods, whereas the purely dynamic effect (i.e., only due to meridional flow changes) accounts for more than $120 \%$ increase, clearly suggesting that the upper ocean thermal change of the inflow is insufficient to explain the large increase in the simulated ocean heat transport into the Atlantic basin.

\section{The Role of South Atlantic and Indian Subtropical Gyres}

[16] The main conclusions so far are that the observed large warming of the Atlantic basin during the latter half of the 20th century is mainly due to the increased ocean heat transport into the Atlantic basin across $30^{\circ} \mathrm{S}$, and that the anomalous northward ocean heat transport at $30^{\circ} \mathrm{S}$ is caused not only by the increased upper ocean temperature at $30^{\circ} \mathrm{S}$ but also, and more strongly, by the increased AMOC at $30^{\circ} \mathrm{S}$.

[17] Remote mechanical and thermal forcing appear to strengthen the AMOC and associated heat transport at $30^{\circ} \mathrm{S}$. In order to understand the mechanisms, it is helpful to explore the simulated pathways of the northward heat transport in the Atlantic Ocean. Shown in Figure 3a are the simulated northward heat transport (contours) and heat transport vector averaged in the upper $3000 \mathrm{~m}$ for 1979-2008, obtained from EXP CTR. It clearly shows that the main pathway of heat into the South Atlantic in this model originates in the Indian Ocean. The key roles played in global climate by the Indian-Atlantic inter-ocean exchange have long been recognized [e.g., Biastoch et al., 2009; Beal et al., 2011]. The warm water that leaks from the Indian Ocean, the so-called Agulhas leakage, into the South Atlantic may affect the strength of the AMOC, both on decadal advective time scales and on faster Rossby wave time scales [e.g., van Sebille and van Leeuwen, 2007]. As shown in Figure 3a, the warm water leaked from the Indian Ocean moves northwestward along the South Atlantic subtropical gyre until it reaches the western boundary, then continues its northward excursion through the cross-hemispheric western boundary current system. The warm water finally arrives at the subpolar Atlantic via the Loop Current, Gulf Stream and North Atlantic Current, respectively. In reality most Agulhas leakage is carried by Agulhas rings, mesoscale features that are not well represented at this model's resolution [e.g., Beal et al., 2011, and references therein]. Nevertheless, the pathways of the heat transport shown in Figure $3 \mathrm{a}$ are very similar to the advective pathways of mass seen in both high- 
resolution models and surface drifters [van Sebille et al., 2011].

[18] Figure $3 \mathrm{~b}$ is identical to Figure 3a except that it shows the difference in the simulated northward heat transport (contours) and heat transport vector between 1979-2008 and 1871-1900 periods. The pathways of the anomalous northward ocean heat transport are surprisingly similar to those of the mean northward ocean heat transport (Figure 3a). It is also clear that the inter-ocean heat transport from the Indian Ocean is increased. This agrees with recent studies in the Agulhas region, on the boundary between the Indian and Atlantic Oceans, which show an increase in both upper ocean temperature [Rouault et al., 2009] and inter-ocean transport [Biastoch et al., 2009] in recent decades. The anomalous anticyclones of the barotropic stream function in the South Atlantic and Indian Ocean between $50^{\circ} \mathrm{S}$ and $30^{\circ} \mathrm{S}$ (Figure S2) further indicate that both the South Atlantic subtropical gyre and Indian Ocean subtropical gyre are strengthened. As shown in Figure 3c, this is consistent with the observed westerly wind anomalies over the Southern Ocean and the associated strengthening of the wind stress curl over the South Atlantic and Indian subtropical gyres, as suggested by earlier high- and low-resolution modeling studies [Biastoch et al., 2009; Sijp and England, 2009]. Note that Ekman transport does not directly contribute to the increased AMOC at $30^{\circ} \mathrm{S}$ since the zonal wind stress at $30^{\circ} \mathrm{S}$ is nearly unchanged (Figure 3c). Since the westerly wind anomalies over the Southern Ocean are largely linked to the Southern Annular Mode (SAM), it appears that the increased AMOC at $30^{\circ} \mathrm{S}$ in EXP CTR is ultimately caused by the increasing trend of the SAM since the mid-20th century. The cause of the SAM trend is not the focus of this study, but one popular hypothesis involves the Antarctic ozone losses with important contributions from anthropogenic chlorofluorocarbons [e.g., Thompson and Solomon, 2002].

\section{Discussions}

[19] Obviously, there remain many crucial questions. One such question is the role of basin-scale low-frequency climate variability such as the Atlantic multidecadal oscillation (AMO) and the Pacific decadal oscillation on the differential inter-ocean warming. In particular, the AMO, which arguably results from the natural oscillation of the AMOC driven in the North Atlantic sinking regions [e.g., Knight et al., 2005; Lee and Wang, 2010], may have directly contributed to the rapid warming of the Atlantic Ocean since the 1950s. As shown in Figure S3a, the simulated North Atlantic Ocean heat content in EXP_ATL exhibits a low-frequency multidecadal signal similar to the observed AMO, almost perfectly reproducing that of EXP CTR prior to the 1960s. In EXP_REM, however, the multidecadal signal during the $1920 \mathrm{~s}-1950 \mathrm{~s}$, which is clearly visible in both EXP CTR and EXP_ATL is completely missing. The absence of this multidecadal signal in EXP_REM suggests that processes internal to the Atlantic Ocean cause the multidecadal swing in EXP CTR prior to the 1960s. During the 1960s-2000s, on the other hand, remote processes seem to have contributed more than internal processes to the large increase in the North Atlantic heat content. The simulated South Atlantic Ocean heat content in EXP CTR and EXP REM is characterized by a monotonic increase after the $\overline{1960 \text { s, whereas }}$ in EXP_ATL there is no apparent change in the South
Atlantic heat content throughout the 20th century. These results lead to a conclusion that remote processes mainly forced the ocean heat content increase in both North and South Atlantic during the 1960s-2000s in EXP_CTR with a moderate contribution by internal processes in the North Atlantic.

[20] There are some limitations in this study. In particular, the CCSM3_POP used as the main tool in this study is not an eddy-resolving resolution model. Therefore, it is important that the major findings of this study are further tested with higher resolution models. In particular, eddy-resolving resolution $(\sim 0.1 \mathrm{deg})$ models are required to properly simulate the role of eddies in the Agulhas leakage region [e.g., Beal et al., 2011]. A related issue is the eddy-driven heat and mass transports in the Southern Ocean, which are not well represented in this study.

[21] A recent observational study [Böning et al., 2008] showed that the meridional overturning circulation in the Southern Ocean is insensitive to the intensification of Southern Hemisphere westerly winds over the past decades because the eddy-driven heat and mass transports largely compensate for the increased Ekman heat and mass transports in the Southern Ocean. Farneti and Delworth [2010] also showed that the AMOC change induced by changes in Southern Hemisphere westerly winds is much reduced in an eddy-resolving coupled climate model in comparison to that in a coarse-resolution model. Therefore, we acknowledge that the simulated $\mathrm{AMOC}$ increase at $30^{\circ} \mathrm{S}$ during the $1950 \mathrm{~s}-2000 \mathrm{~s}$ could be an overestimate. Nevertheless, in our model simulation, the increased $\mathrm{AMOC}$ at $30^{\circ} \mathrm{S}$ is not directly forced by Ekman transport from the Southern Ocean because the zonal wind stress at $30^{\circ} \mathrm{S}$ is unchanged (Figure 3c). Instead, it is indirectly induced by the increased wind stress curl that strengthened the South Atlantic and Indian subtropical gyres and thus enhanced the inter-ocean volume transport from the Indian Ocean. A recent study that uses an eddy-resolving model indeed reported an increased volume transport from the Indian Ocean to the South Atlantic Ocean during the 1970s-2000s [Biastoch et al., 2009], supporting the overall conclusions of this study.

[22] Finally, it is worthwhile to point out that this study uses a surface-forced global ocean-ice coupled model, which does not allow coupled atmosphere-ocean interactions. Therefore, it will be interesting to see if a fully coupled model simulation with realistic radiative forcing over the 20th century supports the main conclusions of this study.

[23] Acknowledgments. We would like to thank the two anonymous reviewers for their thoughtful comments and suggestions, which led to a significant improvement of the paper. This study was motivated and benefited from the AMOC discussion group of the research community at UM/RSMAS and NOAA/AOML. We wish to thank Igor Kamenkovich and all the participants who led the AMOC discussion group during the past year. We also acknowledge helpful suggestions from Ping Chang and Greg Foltz. This work is supported by the National Science Foundation (grant 0850897).

[24] The Editor thanks two anonymous reviewers for their assistance in evaluating this paper.

\section{References}

Barnett, T. P., D. W. Pierce, and R. Schnur (2001), Detection of anthropogenic climate change in the world's oceans, Science, 292, 270-274, doi:10.1126/science. 1058304.

Barnett, T. P., D. W. Pierce, K. M. AchutaRao, P. J. Gleckler, B. D. Santer, J. M. Gregory, and W. M. Washington (2005), Penetration of human- 
induced warming into the world's oceans, Science, 309, 284-287, doi: $10.1126 /$ science. 1112418

Beal, L. M., W. P. M. De Ruijter, A. Biastoch, and R. Zahn, and SCOR/ WCRP/IAPSO Working Group 136 (2011), On the role of the Agulhas system in ocean circulation and climate, Nature, 472, 429-436, doi:10.1038/nature09983.

Biastoch, A., C. W. Böning, F. U. Schwarzkopf, and J. R. E. Lutjeharms (2009), Increase in Agulhas leakage due to poleward shift in the Southern Hemisphere westerlies, Nature, 462, 495-498, doi:10.1038/ nature 08519 .

Böning, C. W., A. Dispert, M. Visbeck, S. R. Rintoul, and F. U. Schwarzkopf (2008), The response of the Antarctic Circumpolar Current to recent climate change, Nat. Geosci., 1, 864-869, doi:10.1038/ngeo362.

Broecker, W. S. (1987), The biggest chill, Nat. Hist., 96, 74-82.

Compo, G. P., et al. (2011), The twentieth century reanalysis project, Q. J. R. Meteorol. Soc., 137, 1-28, doi:10.1002/qj.776.

Doney, S. C., S. Yeager, G. Danabasoglu, W. G. Large, and J. C. McWilliams (2007), Mechanisms governing interannual variability of upper-ocean temperature in a global ocean hindcast simulation, J. Phys. Oceanogr., 37, 1918-1938, doi:10.1175/JPO3089.1.

Dong, S., S. L. Garzoli, M. O. Baringer, C. S. Meinen, and G. J. Goni (2009), Interannual variations in the Atlantic meridional overturning circulation and its relationship with the net northward heat transport in the South Atlantic, Geophys. Res. Lett., 36, L20606, doi:10.1029/ 2009GL039356.

Farneti, R., and T. L. Delworth (2010), The role of mesoscale eddies in the remote oceanic response to altered Southern Hemisphere winds, J. Phys. Oceanogr., 40, 2348-2354, doi:10.1175/2010JPO4480.1.

Grist, J. P., et al. (2010), The roles of surface heat flux and ocean heat transport convergence in determining Atlantic Ocean temperature variability, Ocean Dyn., 60, 771-790, doi:10.1007/s10236-010-0292-4.

Knight, J. R., R. J. Allan, C. K. Folland, M. Vellinga, and M. E. Mann (2005), A signature of persistent natural thermohaline circulation cycles in observed climate, Geophys. Res. Lett., 32, L20708, doi:10.1029/ 2005 GL024233.

Lee, S.-K., and C. Wang (2010), Delayed advective oscillation of the Atlantic thermohaline circulation, J. Clim., 23, 1254-1261, doi:10.1175/ 2009JCLI3339.1.

Lee, S.-K., D. B. Enfield, and C. Wang (2011), Future impact of differential inter-basin ocean warming on Atlantic hurricanes, J. Clim., 24 1264-1275, doi:10.1175/2010JCLI3883.1.

Levitus, S., J. I. Antonov, J. Wang, T. L. Delworth, K. W. Dixon, and A. J. Broccoli (2001), Anthropogenic warming of Earth's climate system, Science, 287, 2225-2229, doi:10.1126/science.287.5461.2225.

Levitus, S., J. I. Antonov, T. P. Boyer, R. A. Locarnini, H. E. Garcia, and A. V. Mishonov (2009), Global ocean heat content 1955-2008 in light of recently revealed instrumentation problems, Geophys. Res. Lett., 36, L07608, doi:10.1029/2008GL037155.

Lozier, M. S., V. Roussenov, S. Mark, C. Reed, and R. G. Williams (2010), Opposing decadal changes for the North Atlantic meridional overturning circulation, Nat. Geosci., 3, 728-734, doi:10.1038/ngeo947.

Lumpkin, R., and K. Speer (2007), Global ocean meridional overturning, J. Phys. Oceanogr., 37, 2550-2562, doi:10.1175/JPO3130.1.

Mignot, J., A. Levermann, and A. Griesel (2006), A decomposition of the Atlantic meridional overturning circulation into physical components using its sensitivity to vertical diffusivity, J. Phys. Oceanogr., 36, 636-650, doi:10.1175/JPO2891.1.

Palmer, M. D., and K. Haines (2009), Estimating oceanic heat content change using isotherms, J. Clim., 22, 4953-4969, doi:10.1175/ 2009JCLI2823.1.

Palmer, M. D., K. Haines, S. F. B. Tett, and T. J. Ansell (2007), Isolating the signal of ocean global warming, Geophys. Res. Lett., 34, L23610, doi:10.1029/2007GL031712.

Rouault, M., P. Penven, and B. Pohl (2009), Warming in the Agulhas Current system since the 1980's, Geophys. Res. Lett., 36, L12602, doi:10.1029/ 2009GL037987.

Sijp, W. P., and M. H. England (2009), Southern Hemisphere westerly wind control over the ocean's thermohaline circulation, J. Clim., 22, 1277-1286, doi:10.1175/2008JCLI2310.1.

Thompson, D. W., and S. Solomon (2002), Interpretation of recent Southern Hemisphere climate change, Science, 296, 895-899, doi:10.1126/science. 1069270.

van Sebille, E., and P. J. van Leeuwen (2007), Fast northward energy transfer in the Atlantic due to Agulhas rings, J. Phys. Oceanogr., 37, 2305-2315, doi:10.1175/JPO3108.1.

van Sebille, E., L. M. Beal, and W. E. Johns (2011), Advective time scales of Agulhas leakage to the North Atlantic in surface drifter observations and the 3D OFES model, J. Phys. Oceanogr., 41, 1026-1034, doi:10.1175/2010JPO4602.1.

M. O. Baringer, D. B. Enfield, S.-K. Lee, and C. Wang, Atlantic Oceanographic and Meteorological Laboratory, NOAA, 4301 Rickenbacker Cswy., Miami, FL 33149, USA. (sang-ki.lee@noaa.gov)

B. P. Kirtman and E. van Sebille, Rosenstiel School for Marine and Atmospheric Science, University of Miami, 4600 Rickenbacker Cswy., Miami, FL 33149, USA.

W. Park, Leibniz Institute of Marine Sciences at University of Kiel (IFM-GEOMAR), Duesternbrooker Weg 20, D-24105 Kiel, Germany.

S. G. Yeager, National Center for Atmospheric Research, PO Box 3000, Boulder, CO 80307, USA. 